\title{
High-sensitivity $\mathrm{SO}_{2}$ Gas Sensor Based on Noble Metal Doped $\mathrm{WO}_{3}$ Nanomaterials
}

\author{
Hang Liu, Jiani Zhou, Lanyi Yu, Qiuchen Wang, Bing Liu, Peihua Li, Yuhong Zhang* \\ School of electrical and computer engineering, Jilin jianzhu university, Changchun 130118, China \\ *E-mail: zhangyuhong@jlju.edu.cn, Liuhang76@163.com
}

Received: 2 September 2021 / Accepted: 12 October 2021 / Published: 10 November 2021

In this paper, the $\mathrm{WO}_{3}$ nanoparticles(NPs) were prepared by a facile and low cost chemical coprecipitation method. Then the Pt- $\mathrm{WO}_{3}$ and $\mathrm{Au}-\mathrm{WO}_{3}$ were synthesized. The morphologies of the samples were represented by XRD and SEM. Sensing characteristics of novel metal doped $\mathrm{WO}_{3}$ sensors were investigated by exposure to $\mathrm{SO}_{2}$ gas at different operating temperature. The sensor response for $\mathrm{SO}_{2}$ gas was measured with different concentrations from $100 \mathrm{ppb}$ to $16 \mathrm{ppm}$. As a result, the $1 \mathrm{wt} \% \mathrm{Pt}-$ $\mathrm{WO}_{3}$ sensor presented a greatly low detection limit of $100 \mathrm{ppb}$ at optimum operating temperature of 160 ${ }^{\circ} \mathrm{C}$. The sensitivity of $1 \mathrm{wt} \% \mathrm{Pt}-\mathrm{WO}_{3}$ sensor for $100 \mathrm{ppb}$ reached 4.1. As well as a better sensor response as compared to the other $\mathrm{SO}_{2}$ gas sensor. It demonstrated that the $\mathrm{Pt}-\mathrm{WO}_{3}$ materials may be used to develop the commercial $\mathrm{SO}_{2}$ gas sensor.

Keywords: $\mathrm{SO}_{2}, \mathrm{WO}_{3}$ nanoparticles, coprecipitation, Sensing characteristics

\section{$\underline{\text { FULL TEXT }}$}

(C) 2021 The Authors. Published by ESG (www.electrochemsci.org). This article is an open access article distributed under the terms and conditions of the Creative Commons Attribution license (http://creativecommons.org/licenses/by/4.0/). 